ARTICLE

\title{
Architecture of the outer-membrane core complex from a conjugative type IV secretion system
}

\author{
Himani Amin (1) ${ }^{1}$, Aravindan Ilangovan (10) ${ }^{2 凶}$ \& Tiago R. D. Costa (i) ${ }^{1 凶}$
}

Conjugation is one of the most important processes that bacteria utilize to spread antibiotic resistance genes among bacterial populations. Interbacterial DNA transfer requires a large double membrane-spanning nanomachine called the type 4 secretion system (T4SS) made up of the inner-membrane complex (IMC), the outer-membrane core complex (OMCC) and the conjugative pilus. The iconic F plasmid-encoded T4SS has been central in understanding conjugation for several decades, however atomic details of its structure are not known. Here, we report the structure of a complete conjugative OMCC encoded by the pED208 plasmid from E. coli, solved by cryo-electron microscopy at 3.3 $\AA$ resolution. This $2.1 \mathrm{MDa}$ complex has a unique arrangement with two radial concentric rings, each having a different symmetry eventually contributing to remarkable differences in protein stoichiometry and flexibility in comparison to other OMCCs. Our structure suggests that F-OMCC is a highly dynamic complex, with implications for pilus extension and retraction during conjugation.

\footnotetext{
${ }^{1}$ MRC Centre for Molecular Bacteriology and Infection, Department of Life Sciences, Imperial College, London SW7 2AZ, UK. ${ }^{2}$ School of Biological and

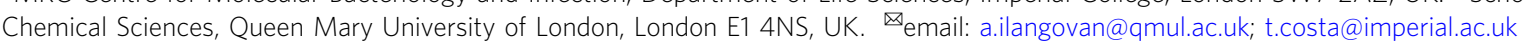


F irst described in the 1940s by Lederberg and Tatum, conjugation is a remarkable phenomenon whereby singlestranded DNA is delivered unidirectionally from a donor to recipient cell in bacteria ${ }^{1}$. As an elaborate form of horizontal gene transfer, this process is crucial for bacterial evolution and influences genome plasticity. Concerningly, it is a major cause for the widespread transmission and persistence of antibiotic resistance amongst bacterial populations ${ }^{2-4}$.

The conjugative transfer is mediated by a type IV secretion system (T4SS); a specialised membrane-embedded secretion machine found in Gram-negative and Gram-positive bacteria ${ }^{5}$. T4SSs are incredibly versatile nanomachines capable of secreting transforming DNA into plant cells ${ }^{6}$ and lethal protein effectors to competing bacteria and eukaryotic cells during infection ${ }^{7-11}$.

Minimal conjugative machineries in Gram-negative bacteria are composed of 12 protein subunits. This includes the archetypal VirB/D system from Agrobacterium tumefaciens, where the T4SS is composed of the proteins VirB1-11 and VirD4, which are organised into an outer membrane core complex (OMCC), an inner-membrane complex (IMC) and an extracellular pilus ${ }^{12-17}$. The canonical OMCC adopts a barrel-shaped architecture consisted of two ringed layers, the outer $(\mathrm{O})$ and inner $(\mathrm{I})$ layers. The overall structure is composed by 14 copies of the VirB7, VirB9 and VirB10 proteins ${ }^{18-20}$. VirB10 proteins span both the inner(IM) and outer-membranes (OM) via their $\mathrm{N}$-terminal domains (NTD) and the two-helix bundle located at the C-terminal domain (CTD) of the proteins ${ }^{19,21}$. The VirB7 lipoproteins are covalently bound to the phospholipid moiety in the inner leaflet of the OM, and together with the CTD of the VirB9 proteins, shape the O-layer of the complex ${ }^{22,23}$. The I-layer consists of VirB9 NTDs and also an extended portion of the VirB10 NTDs extending towards the $\mathrm{IM}^{20,21}$. The high-resolution structure of a complete OMCC from a minimised T4SS derived from the phytopathogenic Xanthomonas citri, has been recently attained 21,24 . The structure, solved by single-particle cryo-electron microscopy (cryo-EM), unveiled the atomic configuration that full-length VirB7, VirB9 and VirB10 proteins adopt to shape the entire OMCC. Interestingly, and despite the close similarities with other minimised T4SS (e.g., A. tumefaciens VirB, pKM101 and R388), the VirB7 lipoprotein features a globular N0 domain at its CTD with a fold similar to proteins associated with other bacterial secretion systems ${ }^{25}$. This domain extends out from the central core of the OMCC, thus shaping the "flying saucer" configuration of the complex.

The extended conjugative T4SS encoded by members of the F-plasmids (e.g., pED208) are responsible for the emergence of multi-antibiotic resistant in a wide range of pathogenic strains ${ }^{26}$. F plasmid-encoded T4SSs are remarkably more complex than the minimised T4SS counterparts (e.g., virB, pKM101 and R388) and are the only able to extend and retract their pilus during conjugation $^{2}$. The tra gene operon within the pED208 plasmid encodes $\sim 25$ different proteins (Fig. 1a) involved in different steps of ssDNA transfer during conjugation e.g., T4SS assembly, pilus biogenesis and dynamics, mating pair stabilisation and entry exclusion, relaxosome assembly and regulation ${ }^{27}$. Within the tra region, at least ten proteins share homology to the VirB/D system $^{28}$. This includes the three proteins, TraV, TraK and TraB, which assemble the OMCC (F-OMCC), and show homology to VirB7, VirB9 and VirB10, respectively ${ }^{29}$ (Supplementary Fig. 2). Our understanding of how the F-pili assembles at the cell surface and the organisation of the T4SS at the base has been shaped by recent structural advancements which include the atomic structure of the F-pilus and the in situ cryo-electron tomography analysis of the F-T4SS ${ }^{30,31}$. This analysis showed the F-OMCC adopting a 13-fold symmetry; a symmetry that has only been observed in the OMCC structure from the infectious
Dot/Icm T4SS from Legionella pneumophila ${ }^{32-34}$. Despite these recent advances, we still lack atomic details on the architecture of conjugative OMCCs from both minimal and extended T4SSs. Importantly, these structures will help us decipher mechanistic details of pilus dynamics and DNA transport during conjugation that can be exploited to suppress antibiotic resistance dissemination.

Here, we present the structure of an outer-membrane core complex from the iconic F-T4SS encoded by the E. coli pED208 plasmid solved by single-particle cryo-electron microscopy at $3.3 \AA$ resolution. This $2.1 \mathrm{MDa}$ structure, provides an atomic model of the TraB, TraK and TraV proteins and unveils unique stoichiometry relationships between the three proteins. Surprisingly, the complex is formed by two highly flexible concentric rings made by a total of 69 proteins chains arranged in two distinct symmetries. Strikingly, TraK and TraV proteins adopt multiple conformations within one of the complex rings and TraB and TraV can exist in both areas of symmetry. Our model reveals an exceptional protein organisation within the F-OMCC that could account for the high flexibility of the complex. Such flexibility might be pivotal to accommodate the unique dynamic properties (extension and retraction) of the F-pilus during conjugation.

\section{Results}

Purification and cryo-EM reconstruction of the F-T4SS outer membrane core complex (OMCC). The outer-membrane core complex (OMCC) proteins $\mathrm{TraB}$, TraK and TraV are part of the F-T4SS encoded in the tra region of the conjugative pED208 plasmid from E. coli $^{29}$ (Fig. 1a). The three OMCC genes were cloned, over-expressed and the complex purified from E. coli membranes using affinity and gel filtration chromatography (Fig. 1b, c). The correct protein bands in the SDS-PAGE gel were verified by LC-MS/MS. Upon purification, the integrity and homogeneity of the complex were accessed by negative-stain EM (Fig. 1d) before vitrification in a thin carbon layer and imaging by cryo-EM (Fig. 1e). A cryo-EM dataset of $\sim 1.45$ million particles yielded well-resolved $2 \mathrm{D}$ class averages showing different orientations of the complex in the ice (Fig. 1f). Surprisingly, on close inspection of the top/bottom $2 \mathrm{D}$ class averages, we could readily identify two distinct areas of symmetries (C17 and $\mathrm{C} 13$ ), one defining a central inner ring $\left(\mathrm{OMCC}_{\mathrm{IR}}\right)$ and the other a peripheral outer ring $\left(\mathrm{OMCC}_{\mathrm{OR}}\right)$ in the complex (Fig. 1f).

Based on the symmetry information obtained from the 2D class averages, we masked the $\mathrm{OMCC}_{\mathrm{IR}}$ and $\mathrm{OMCC}_{\mathrm{OR}}$ regions from our initial low-resolution map, generating two individual highresolution maps correlating with the $\mathrm{C} 17\left(\mathrm{OMCC}_{\mathrm{IR}}\right)$ and $\mathrm{C} 13$ $\left(\mathrm{OMCC}_{\mathrm{OR}}\right)$ rings (Fig. 2a, b). Independent homogeneous refinement of the data yielded two maps with an overall average resolution of $3.3 \AA\left(\mathrm{OMCC}_{\mathrm{IR}}\right)$ and $3.4 \AA \quad\left(\mathrm{OMCC}_{\mathrm{OR}}\right)$ both extending locally to $3.1 \AA$ (Fig. 2 and Supplementary Fig. 1). Segments corresponding to the $\mathrm{OMCC}_{\mathrm{IR}}$ asymmetric unit ( $\mathrm{ASU}_{\mathrm{IR}}$ ) and $\mathrm{OMCC}_{\mathrm{OR}}$ asymmetric unit $\left(\mathrm{ASU}_{\mathrm{OR}}\right.$ ) were identified in the maps and used to build the atomic model of the entire unit. In the $\mathrm{ASU}_{\mathrm{IR}}$, an atomic model of the TraB C-terminal domain (CTD) and TraV N-terminal domain (NTD) could be built and refined into the electron density (Fig. 2c). Unexpectedly, the $\mathrm{ASU}_{\mathrm{OR}}$ segment of the map revealed densities to build and refine more than one molecule of TraK and TraV (Fig. 2a, b). Indeed, densities to fit two NTD and CTD domains of TraK (TraK1 and TraK2) were identified. Similarly, densities corresponding to two $\mathrm{TraV}_{\mathrm{CTD}}$ $\left(\mathrm{TraV} 1_{\mathrm{CTD}}\right.$ and $\left.\mathrm{TraV} 2_{\mathrm{CTD}}\right)$ were also observed in the $\mathrm{ASU} \mathrm{OR}_{\mathrm{O}}$ segment. An additional streak of density adjacent to the TraK $1_{\text {NTD }}$ density was noticed in the inner wall of the OMCC $_{\mathrm{OR}}$ channel corresponding to TraB residues 177-186 (Supplementary Fig. 3b). 
a

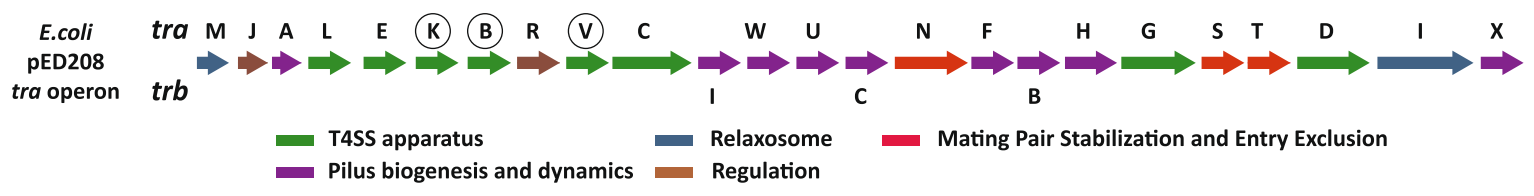

b

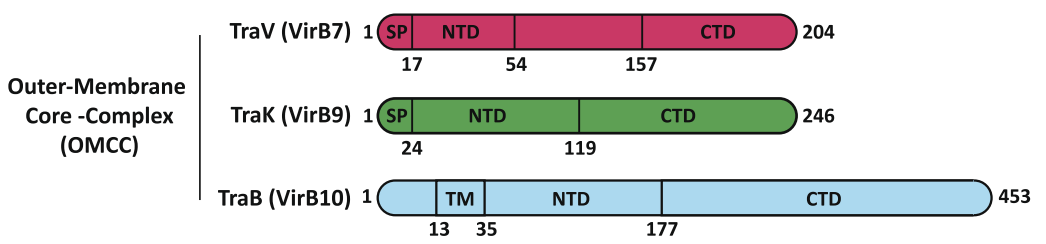

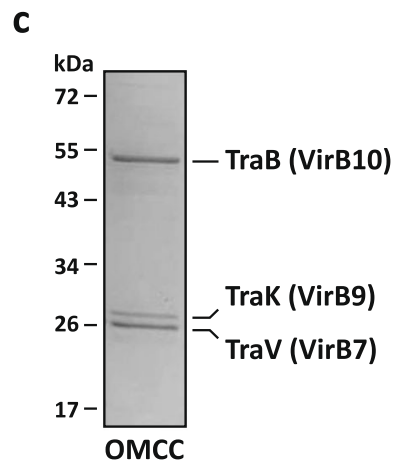

d

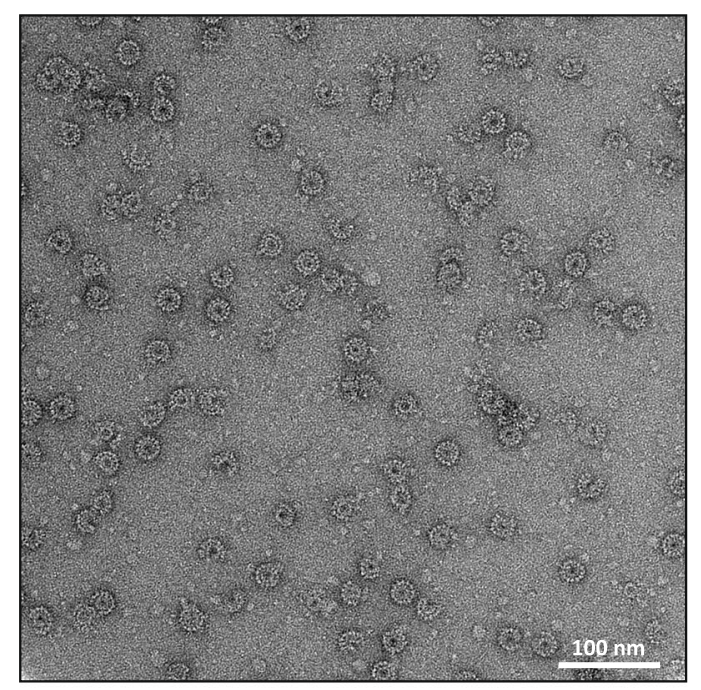

e

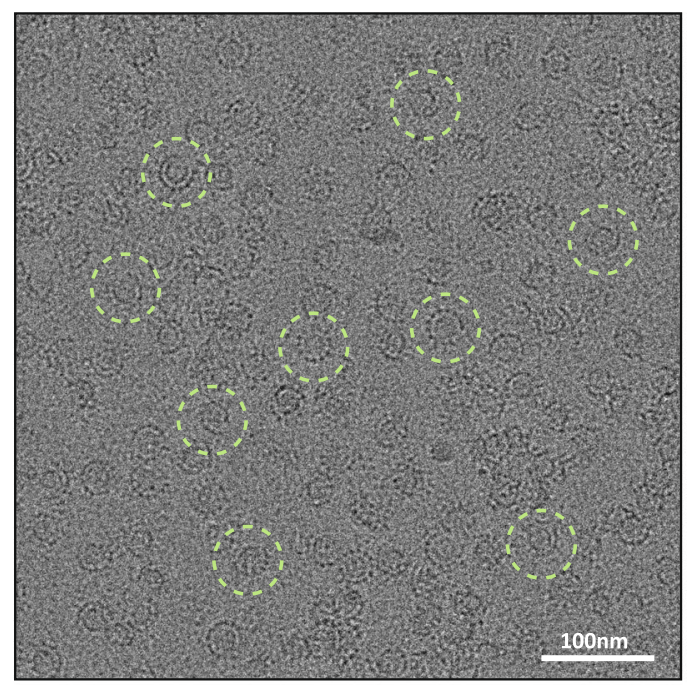

f

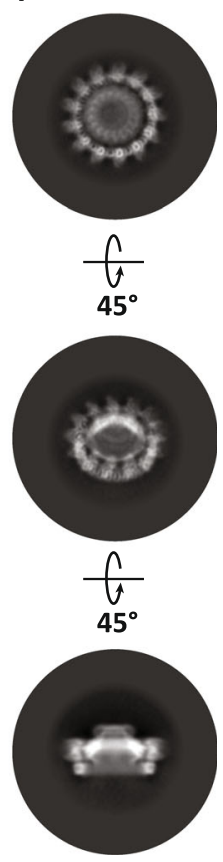

Fig. 1 The genetic organisation, biochemistry and EM analysis of the F plasmid outer membrane complex. a The native arrangement of T4SS-associated genes within the pED208 tra operon with the arrows representing the genes encoding for the T4SS apparatus (green), relaxosome components (blue), mating pair stabilisation and entry exclusion (red), pilus biogenesis and dynamics (purple), and regulation (brown). b The primary sequence structure of the three proteins TraV (purple), TraK (green) and TraB (cyan) including their domains and boundaries. c SDS-PAGE of the OMCC with the bands of the proteins TraB (VirB10), TraK (VirB9) and TraV (VirB7). d Negative stained EM micrograph of the OMCC. Scale bar $100 \mathrm{~nm}$. e Cryo-EM micrograph of the OMCC, with particles highlighted with green circles. Scale bar $100 \mathrm{~nm}$. f Representative top-, tilted- and side-view 2D class averages obtained using CryoSparc v3.1.0 (see 'Methods' section for detailed information).

The atomic structures of the $\mathrm{OMCC}_{\mathrm{IR}}$ and $\mathrm{OMCC}_{\mathrm{OR}}$ asymmetric units. Models of the $\mathrm{TraB}_{\mathrm{CTD}}$ and $\mathrm{TraV}_{\mathrm{NTD}}$ protein chains were built in the $\mathrm{OMCC}_{\mathrm{IR}}$ map, while models for TraK1, TraK2, TraV1 $1_{\text {CTD }}$, TraV2 $2_{\text {CTD }}$ and $\operatorname{TraB}_{\mathrm{CTD}(177-186)}$ were built in the $\mathrm{OMCC}_{\mathrm{OR}}$ map (Fig. 3a). A significant proportion of the $\mathrm{ASU}_{\mathrm{OR}}$ is constituted by TraK where two chains are present per ASU. The TraK $K_{N T D}$ is made up of nine $\beta$ strands $(\beta 1-\beta 9)$ in two sheets making a $\beta$ sandwich domain arrangement (Fig. $3 b, c)$. Two such domains from the respective TraK chains (TraK1 and TraK2) are present in a front-to-back arrangement and extensive salt bridge, hydrogen bond and hydrophobic interactions stabilise their interaction (Supplementary Table 1). The structure of the TraK NTD shows the highest degree of structural homology with its pKM101 $\mathrm{TraO}_{\mathrm{CTD}}$ and $X$. citri VirB10 ${ }_{\mathrm{NTD}}$ counterparts (Supplementary Fig. 5). The TraK $\mathrm{CTD}_{\mathrm{C}}$ is made of two a helices ( $\alpha 1$ and $\alpha 2)$ and six $\beta$ strands $(\beta 10-\beta 15)$ (Fig. $3 b, c)$. For TraK2, the NTD and CTD are connected by a short linker, essentially placing the CTD closer to the NTD. In the case of TraK1 however, the NTD and CTD are further apart connected by an extended linker that is achieved by the melting of $a 1$ in TraK2 (Fig. $3 b, c)$. The two TraK CTDs are arranged with TraK1 on top of TraK2 and are related by a P2 symmetry. These two TraK CTDs are held 
(OMCC)

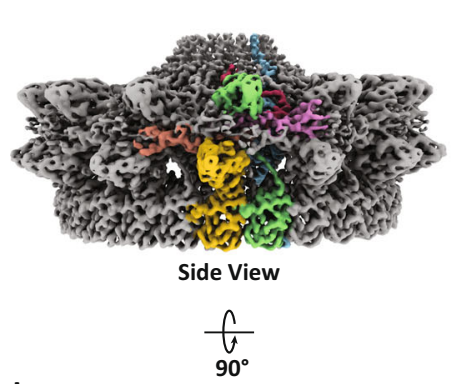

b
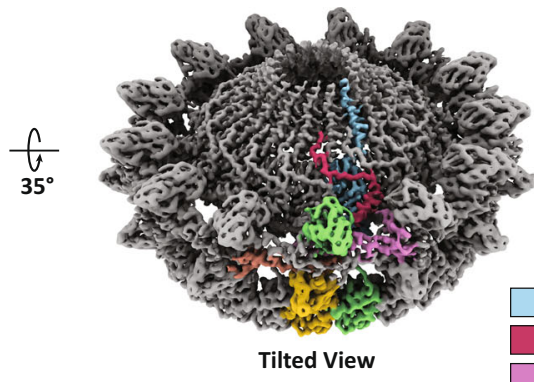

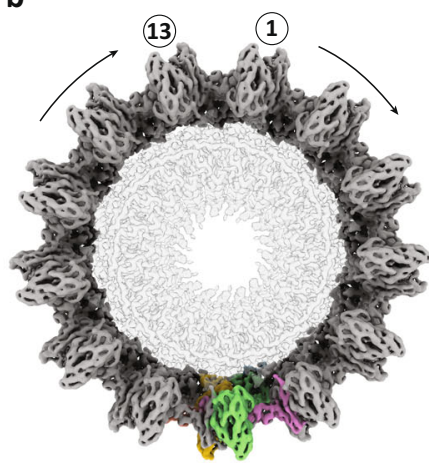

Top View Outer-Ring $\left(\mathrm{OMCC}_{\mathrm{OR}}\right)$

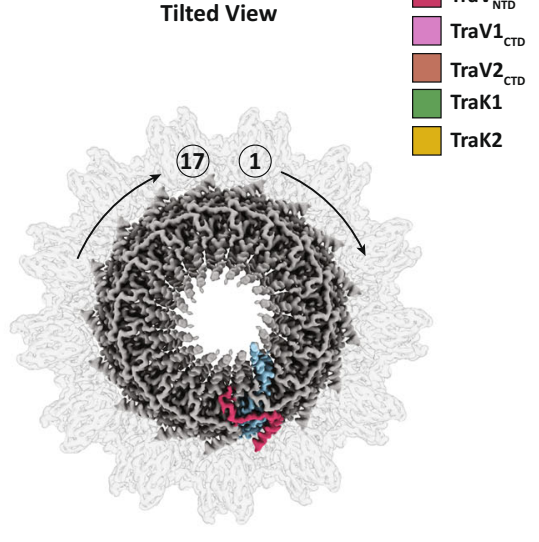

Top View Inner-Ring (OMCC $\left.{ }_{1 \mathrm{R}}\right)$

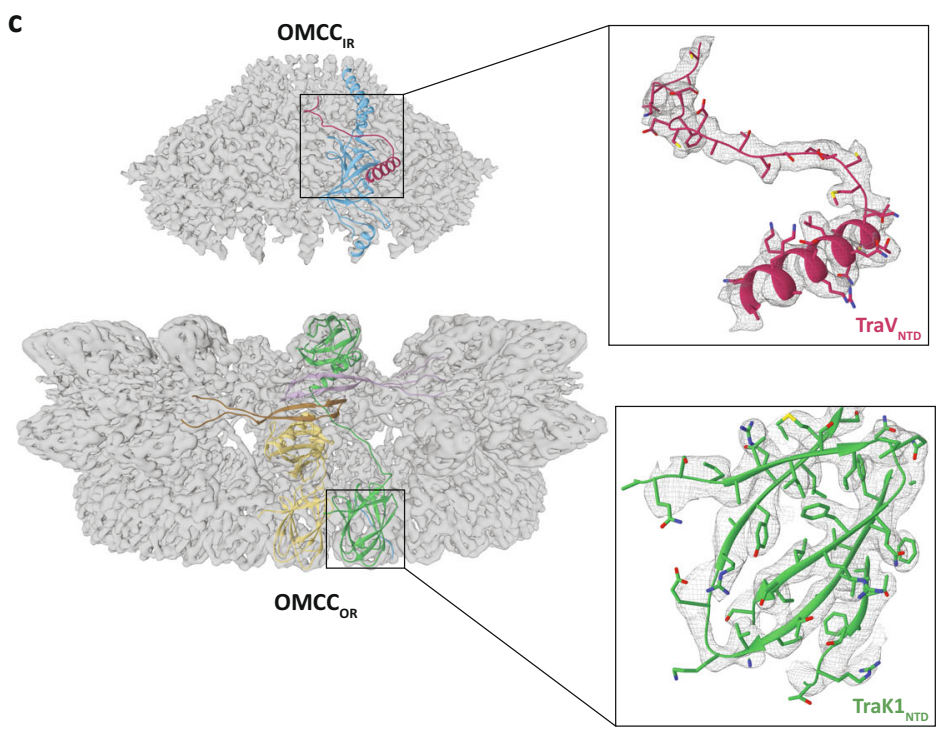

Fig. 2 Cryo-EM map and model of the OMCC. a Overview of the side- and tilted-view of the electron density map of the complete OMCC with the asymmetric unit highlighted with the colour of the respective individual proteins. $\mathbf{b}$ Top view of the electron density map of the full OMCC highlighting the outer-ring (left) and inner-ring (right) symmetries and their respective asymmetric unit protein densities. c Electron density of the OMCC $\mathrm{I}_{\mathrm{R}}$ (top) and $\mathrm{OMCC}_{\mathrm{OR}}$ (bottom) with the asymmetric unit docked into their respective density. The top right shows the refined TraV $\mathrm{V}_{\mathrm{NTD}}$ (purple) model in its density and the bottom right shows the refined TraK1 $1_{\text {NTD }}$ (green) model in its density.

together by two anti-parallel TraV chains that wraps the stem of the TraK linkers ( $\alpha 1-$ TraK2 and $\alpha 2$ - TraK1) (Supplementary Fig. 3a). TraV has four $\beta$ strands per chain making two continuous $\beta$-sheets with TraV1 and TraV2 that stabilise the entire $\mathrm{OMCC}_{\mathrm{OR}}$ complex (Fig. 3b, $\mathrm{c}$ and Supplementary Fig. 3a). A short linker sequence (residues 69-80) assigned to TraV1 and positioned adjacent to TraK $1_{\mathrm{CTD}}$, provides one of the key connections between the inner and the outer rings of the OMCC (Fig. 3b, c). The N-terminal end of the TraV (residues 17-54) is located entirely in the inner ring which includes a single helix al (Fig. 3b, c and Supplementary Fig. 3c). The structure of TraV appears to be unique and does not show structural homology with any of the reported OMCC protein structures. The ASU $\mathrm{IR}_{\text {is }}$ predominantly made up of $\operatorname{TraB}_{\mathrm{CTD}}$ which includes a total of 
a
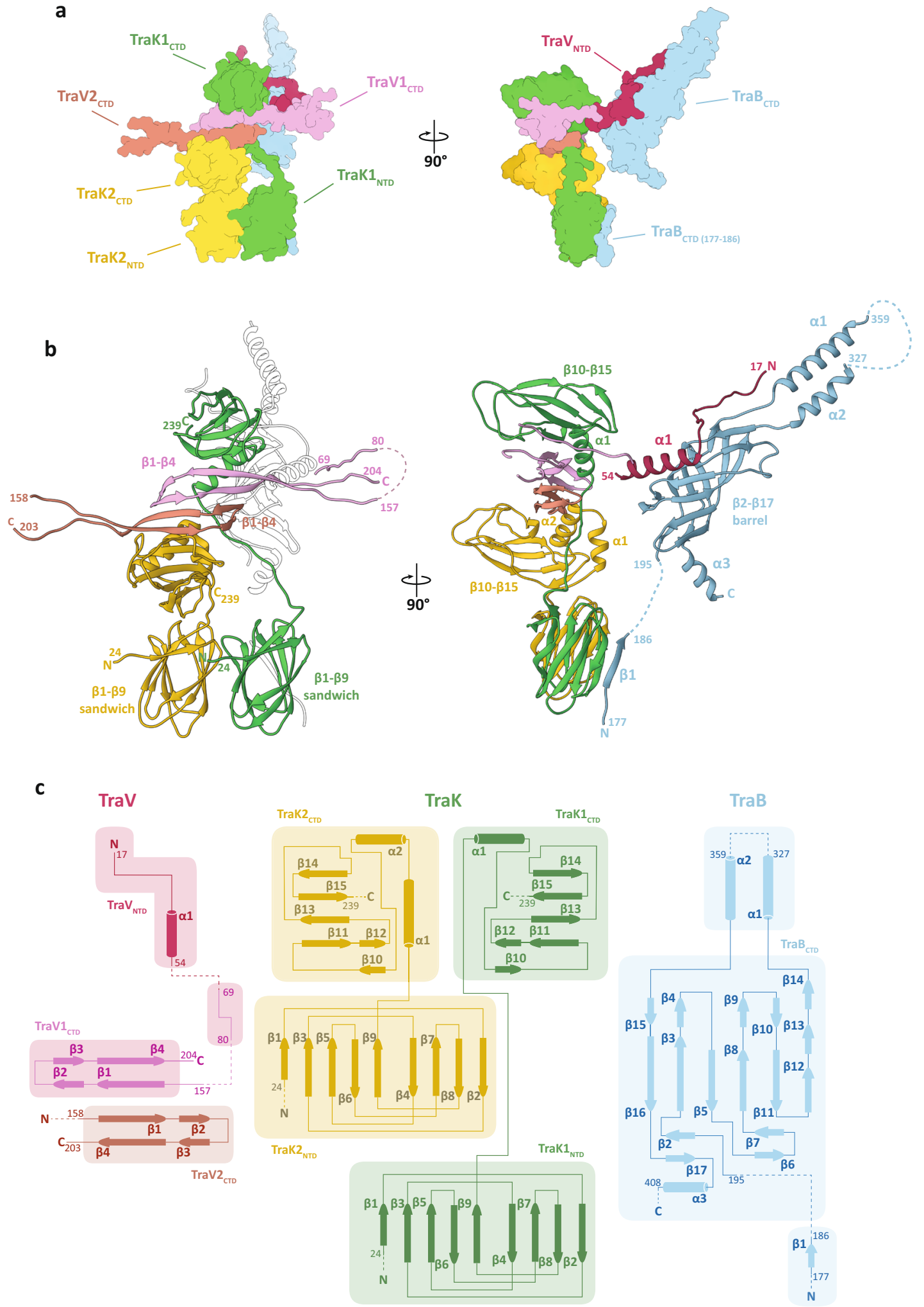

Fig. 3 The combined asymmetric units of the OMCC. a The side- and a $90^{\circ}$ rotated view of the combined OMCC asymmetric units (ASU $\mathrm{OR}_{\mathrm{R}}$ and $\left.A S U_{I R}\right)$ in surface representation, highlighting individual protein and protein domains. Individual proteins colour coded as described in Fig. 2a. b Cartoon representation of the combined ASU ( $A S U_{O R}$ and $A S U_{\mathbb{R}}$ ) with same views as in 'a', colour coded as in Fig. 2a. The individual domains and key secondary structural features along with the protein boundaries are highlighted. c Topology secondary structure diagrams of TraV (purple, pink and brown), TraK (yellow and green) and TraB (cyan). $\beta$-strands and $\alpha$-helices are represented as arrows and cylinders, respectively. Regions for which no electron density was observed are indicated by dashed lines. 
seventeen $\beta$ strands and three $\alpha$ helices. Six of these strands ( $\beta 3$, $\beta 5, \beta 8, \beta 14-\beta 16)$ mediate the interaction with $\operatorname{TraV}_{\text {NTD }}$ (Supplementary Fig. $3 c$ ). The core of the structure has a $\beta$ barrel that connects to two anti-parallel $\alpha$ helices ( $\alpha 1$ and $\alpha 2$ ) and a third helix ( $\alpha 3$ ) towards the $\mathrm{C}$-terminal end. The structure of TraB $\mathrm{B}_{\mathrm{CTD}}$ is highly conserved amongst the closest homologues of TraB (Supplementary Fig. 5), as are the protein sequences within this region (Supplementary Fig. 2a), thus making it an essential structural feature in the T4SS architecture ${ }^{21,28}$. TraB also extends into the outer ring with a short stretch of sequence (residues 177-186) at the N-terminal end of the CTD. This short sequence folds into a $\beta$-strand eventually adding to one of the sheets within the TraK1 $\beta$ sandwich (Fig. 3b, c and Supplementary Fig. 3b). Details of the residues that mediate the interaction between each of the protein chains within the $\mathrm{ASU}_{\mathrm{IR}}$ and $\mathrm{ASU}_{\mathrm{OR}}$ can be found in Supplementary Table 1.

Interactions network between neighbouring ASUs in the

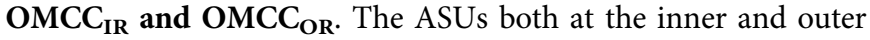
ring make extensive contact with its adjacent units stabilising the entire OMCC structure. In the inner ring, seventeen $\mathrm{ASU}_{\mathrm{IR}}$ heterodimers made of $\mathrm{TraB}_{\mathrm{CTD}}$ and $\mathrm{TraV}_{\mathrm{NTD}}$ (labelled -8 to +8 in the clockwise direction) assemble to form the complete $\mathrm{OMCC}_{\mathrm{IR}}$ (Fig. 4a). A single $\mathrm{ASU}_{\mathrm{IR}}$ makes contact with four other neighbouring ASUs, involving two ASUs each in the clockwise and anti-clockwise direction (Fig. 4a, b). The central reference $A_{S U_{I R}}$ numbered 0, (chains A and B) interacts with ASUs +1 (chain E and F), ASU +2 (chain I and J), ASU-1 (chain C and D) and ASU-2 (chain G and H) (Fig. 4b). ASU +2 bury a surface area of $178 \AA^{2}$ whereas ASU-2 bury a surface area of $172 \AA^{2}$ on ASU- $0_{I R}$. The ASUs +1 and -1 are contiguous to ASU- $0_{\text {IR }}$ and hence bury a much larger surface area of $2481 \AA^{2}$ and $2435 \AA^{2}$, respectively (Fig. 4c, d). Extensive inter ASU interactions stabilise the $\mathrm{OMCC}_{\mathrm{IR}}$ including salt bridge, hydrogen bond and hydrophobic interactions (Supplementary Table 2). Notably, an inter TraV $V_{\text {NTD }}$ di-sulphide bond has been observed between residue Cys35 of chain B and Cys27 of chain D. This interchain di-sulphide bond between contiguous $\operatorname{TraV}_{\text {NTD }}$ chains creates a wide mesh that spreads over the TraB proteins and extends to the periphery of the OMCC $_{\mathrm{IR}}$ (Supplementary Fig. 4). The cysteine residues involved in the di-sulphide bond are only conserved in TraV homologues belonging to the F-T4SS family (Supplementary Fig. 2c, d). In addition, the lipidated and highly conserved Cys 18 of chain B is stabilised by interaction with Tyr366 of chain I through its main chain oxygen $\mathrm{l}^{35}$ (Supplementary Figs. 2c, d and 4). For the outer ring, thirteen $\mathrm{ASU}_{\mathrm{OR}}$ heteropentamers made of TraK1, TraK2, TraV1 $1_{\text {CTD }}$, TraV2 $2_{\text {CTD }}$ and $\operatorname{TraB}_{\mathrm{CTD}(177-186)}$ (labelled -6 to +6 in the clockwise direction) assemble to form the complete $\mathrm{OMCC}_{\mathrm{OR}}$ (Fig. 4e). Each ASU makes contact with another ASU both in the clockwise and anti-clockwise direction. The central reference $\mathrm{ASU}_{\mathrm{OR}}$ numbered 0, (chains $\mathrm{A}, \mathrm{B}, \mathrm{C}, \mathrm{D}$ and $\mathrm{E}$ ) interacts with ASU + 1 (chains K, L, M, N and O) and ASU-1 (chains F, G, $\mathrm{H}$, I and $\mathrm{J}$ ) (Fig. 4f). $\mathrm{ASU}_{\mathrm{ORs}}+1$ and -1 are contiguous to ASU- $0_{\mathrm{OR}}$ and bury a surface area of $2759 \AA^{2}$ and $2671 \AA^{2}$, respectively (Fig. 4g, h). Extensive interactions between contiguous $\mathrm{TraK}_{\mathrm{NTDs}}$ from adjacent ASUs stabilise the $\mathrm{OMCC}_{\mathrm{OR}}$. These inter

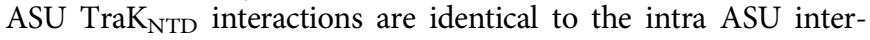
actions observed between TraK1 and TraK2 NTDs (chains A and E) (Fig. 4 f and Supplementary Tables 1 and 2). Adjacent ASUs are also stabilised by interactions between TraV CTDs which include mostly hydrophobic interactions between chain $\mathrm{C}$ and $\mathrm{H}$, and between chain $\mathrm{D}$ and I. In addition, hydrogen bond interactions are also observed between chain $\mathrm{C}$ and $\mathrm{H}$ and between chain $\mathrm{D}$ and $\mathrm{I}$ (Fig. 4f).
The architecture of the complete F-OMCC. The interactions described in the above sections contribute towards the oligomeric assembly of the two rings to form the complete F-OMCC. The inner ring is made of seventeen chains of TraB and TraV proteins each, making a total of 34 chains. The outer ring is made of 26 chains of TraK and TraV each, and 13 chains of TraB, making a total of 65 chains. The inner and outer ring are intricately connected, where 13 of the 17 TraB chains belonging to the inner ring contact the inside surface of the outer ring. The seventeen of the 26 TraV chains of the outer ring extend into the inner ring stabilising the OMCC through a wide protein mesh described earlier (Supplementary Fig. 4). This unusual arrangement between the two OMCC rings ultimately make the complete F-OMCC constructed by 69 polypeptide chains. This complex has overall dimensions of $115 \AA$ in height, $268 \AA$ in diameter and a narrow $50 \AA$ exit channel shaped by TraB $\alpha 1$ and $\alpha 2$ helices (Fig. $5 a-c)$. The TraB $\alpha 1$ helix and TraV NTD residues Gly17-Ser23 define a rim-ward hydrophobic surface suggesting that this portion of the OMCC is likely embedded in the bacterial OM (Fig. 5e). The hydrophobic rim-ward defined mostly by TraB al has a height of $\sim 30 \AA$ and is in agreement with the hydrophobic surface height observed in the O-layer of the functionally related pKM101 T4SS ${ }^{19}$. Conjugative OMCCs seem to be part of a small number of alpha-helical embedded outermembrane complexes in bacterial secretion systems ${ }^{5}$. The proteins $\mathrm{TraB}_{\mathrm{CTD}}$, TraV, TraK $\mathrm{CTD}_{\mathrm{C}}$ define the O-layer and the $\mathrm{TraK}_{\mathrm{NTD}}$ define the I-layer regions of the complex (Fig. 5d). The complex makes a central hollow segment with two chambers, a lower I-chamber outlined by the I-layer and a conical O-chamber outlined by the O-layer (Fig. 5d). The conical O-chamber has an internal diameter of $110 \AA$ at the periplasmic side and constricts into an exit channel towards the outer membrane (Fig. 5d). The diameter of the exit channel $(50 \AA)$ is too narrow to accommodate the $87 \AA$ external diameter of the F-pilus, thus our structure likely represents the F-OMCC in its closed state. It is noteworthy that the exit channel is likely to undergo structural rearrangements to accommodate a growing pilus during pilus biogenesis.

TraV and TraB facilitate flexible contacts between the $O M C C_{I R}$ and the $\mathrm{OMCC}_{\mathrm{OR}}$. In order to address the symmetry mismatch between the $\mathrm{OMCC}_{\mathrm{IR}}$ and the $\mathrm{OMCC}_{\mathrm{OR}}$ we processed the same dataset of particles and generated a 3D map without applying any symmetry parameters (Table 1). This unsymmetrized map showed clear C13 and C17 symmetries matching the position of the outer and inner ring models obtained from the symmetrized maps (Fig. 6a). This map has an average resolution of $5.7 \AA$ to which we were able to dock the atomic model of the $\mathrm{OMCC}_{\mathrm{IR}}$ and the $\mathrm{OMCC}_{\mathrm{OR}}$. Although most parts of the two models fit into the map density, some radial segments at the interface between the $\mathrm{OMCC}_{\mathrm{IR}}$ and the $\mathrm{OMCC}_{\mathrm{OR}}$ lack densities (Fig. 6b, c). At the Olayer, connections between the inner and outer ring of the OMCC are established by a flexible stretch of 14 amino acids (residues

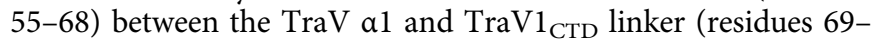
80) that are invisible in the C1 map. This lack of density implies a high degree of flexibility between both rings mediated by this O-layer flexible linker. This flexibility also extends onto the a1 helix where some protomers exhibit variable degrees of electron density in the $\mathrm{C} 1$ map suggesting possible rotational movement between the two OMCC rings (Fig. 6b). The OMCC inner- and outer rings are also connected by a proline-rich eight residue linker (residues 187-194) connecting $\operatorname{TraB} \beta 1$ and $\beta 2$ at the I-layer. A continuous density corresponding to this linker can be observed for a few protomers in the $\mathrm{C} 1 \mathrm{map}$, however, most of the linker connections are absent in the same map (Fig. 6c). This absence of density for the I-layer linkers again suggests some degree of flexibility between the two OMCC rings exists. Overall, 
a

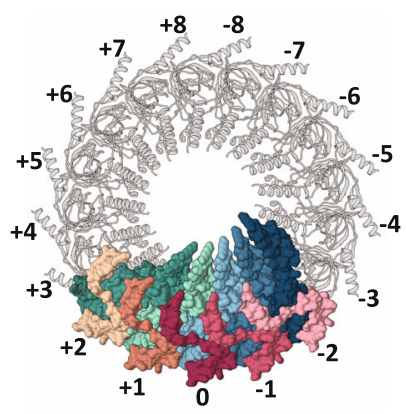

C

\begin{tabular}{l|c}
$\begin{array}{l}\text { Interacting } \\
\text { ASU }_{\mathbb{R}} \text { chains }\end{array}$ & Surface Area $\left(\AA^{2}\right)$ \\
\hline Chain C & $\mathbf{1 8 9 4}$ \\
Chain D & $\mathbf{5 4 1}$ \\
Chain E & $\mathbf{2 0 2 4}$ \\
Chain F & 457 \\
Chain G & 0 \\
Chain H & 172 \\
Chain I & $\mathbf{1 7 8}$ \\
Chain J & 0
\end{tabular}

e

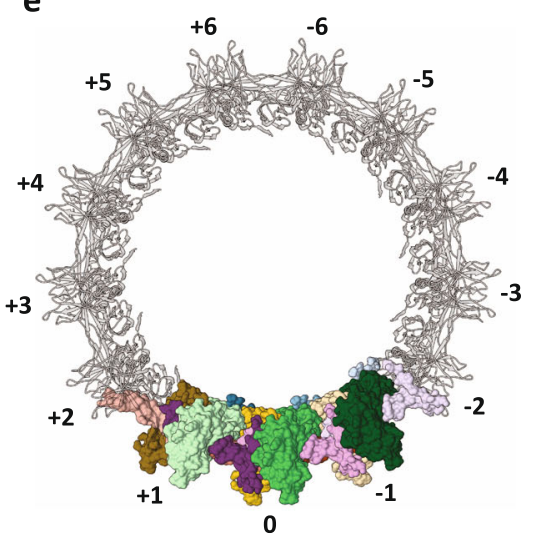

g

\begin{tabular}{|c|c|}
\hline $\begin{array}{l}\text { Interacting } \\
\text { ASU }_{\text {OR }} \text { chains }\end{array}$ & Surface Area $\left(\AA^{2}\right)$ \\
\hline Chain F & 1010 \\
\hline Chain G & 246 \\
\hline Chain $\mathrm{H}$ & 350 \\
\hline Chain I & 1065 \\
\hline Chain $J$ & 0 \\
\hline Chain K & 140 \\
\hline Chain L & 850 \\
\hline Chain M & 1210 \\
\hline Chain N & 334 \\
\hline Chain 0 & 225 \\
\hline
\end{tabular}
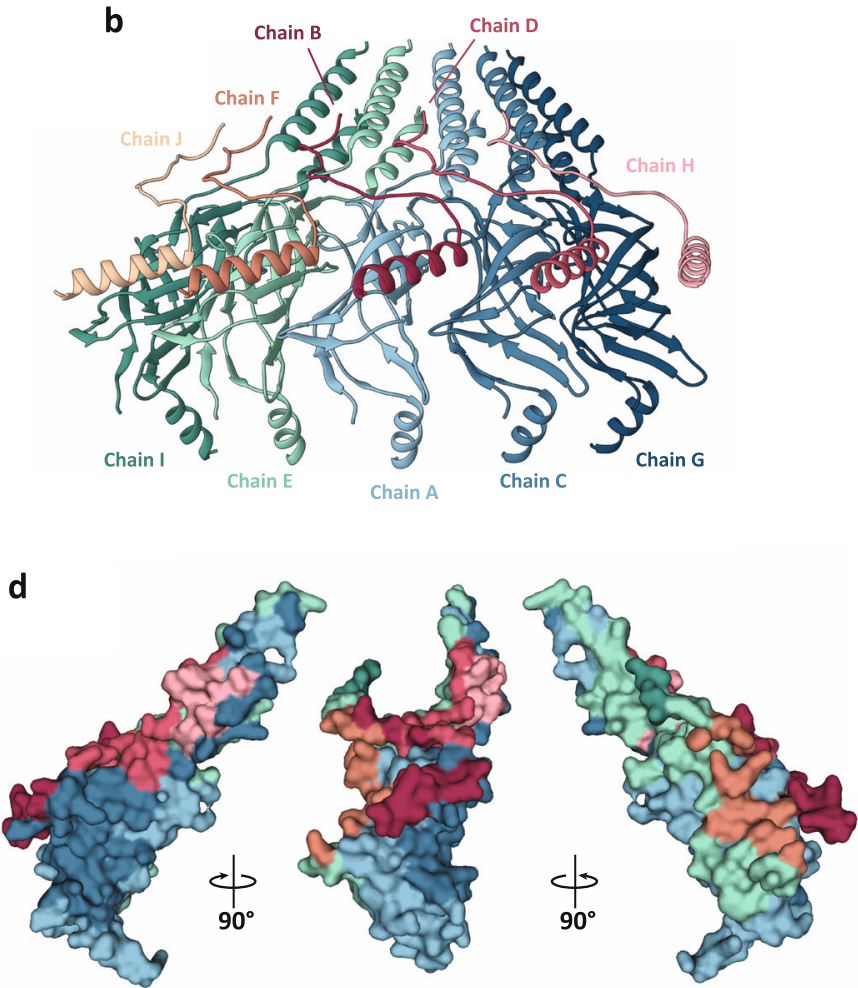

$\mathbf{f}$

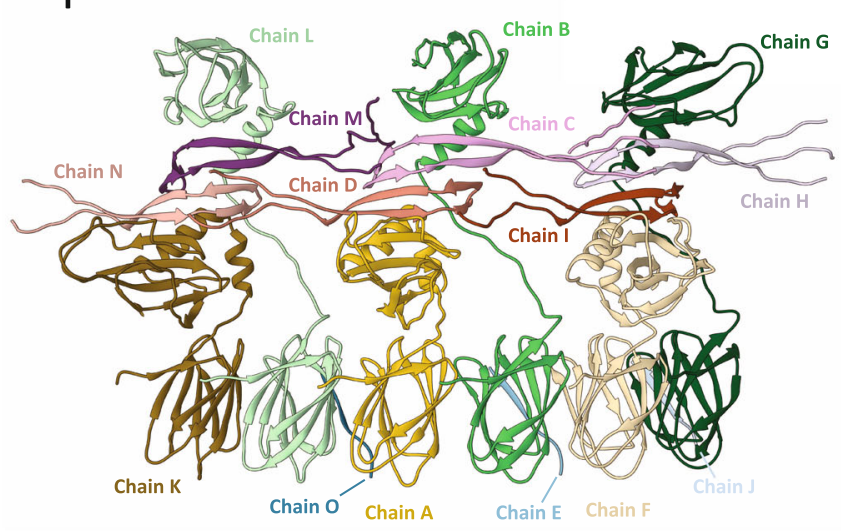

h
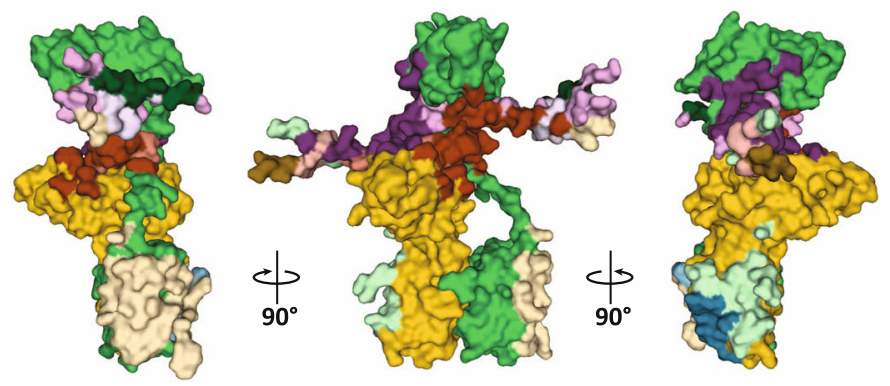

flexibility controlled at two independent locations (I-layer and Olayer), suggest a highly dynamic complex capable of adapting to pilus extension and retraction during conjugation.

\section{Discussion}

The structure of the OMCC from the iconic F plasmid reported here reveals the atomic model of a complete outer membrane core complex from a conjugative secretion system. The components that make up this complex include the proteins TraB, TraK and TraV which are homologous to VirB10, VirB9 and VirB7 respectively and are observed throughout the multi-functional T4SS spectrum ${ }^{28,29}$. Among the conjugative T4SS structures reported so far, all OMCCs have been shown to adopt an homogeneous C14 symmetry throughout the complex ${ }^{18-20}$. 
Fig. 4 Interaction between ASUs in the OMCC. a Top view of the $O M C C_{\mathbb{I R}}$ with the surface representation of five ASUs, the central ASU- $O_{I R}$ and its interacting ASUs $+1,+2,-1$ and -2 . The TraB and TraV of ASU- $O_{\mathbb{I R}}$ are colour coded as described in Fig. 2 a. TraB of the $+1,+2,-1$ and -2 ASUs are coloured in light green, dark green, light blue and dark blue, respectively, and TraV of the $+1,+2,-1$ and -2 ASUs are coloured in brown light brown, pink and light pink, respectively. b Side view of the five ASU in cartoon representation colour coded as described in ' $\mathbf{a}$ '. c Surface area buried in ASU- $\mathrm{O}_{\mathrm{IR}}$ by interacting protein chains. d Mapping of interacting chain-ASU interactions onto ASU- $\mathrm{O}_{\mathbb{R}}$. The interactions made by the neighbouring ASU chains are mapped onto $A S U-O_{I R}$ using the same colour code as ' $a$ '. e Top view of the OMCC $C_{O R}$ with the surface representation of three ASUs, the central ASU- $0_{O R}$ and its interacting ASUs +1 and -1 . The TraB, TraK and TraV of ASU- $0_{O R}$ are colour coded as described in Fig. $2 \mathrm{a}$. TraB of the +1 and -1 ASUs are coloured as dark blue and light blue respectively, TraK1 of the +1 and -1 are coloured in light green and dark green, TraK 2 of the +1 and -1 are coloured in dark brown and light yellow, respectively, TraV1 of the +1 and -1 are coloured in dark pink and light pink, TraV2 of the +1 and -1 are coloured in light orange and brown, respectively. $\mathbf{f}$ Side view of the three ASU in cartoon representation colour coded as described in ' $\mathbf{e}$ '. $\mathbf{g}$ Surface area buried in ASU- $\mathrm{O}_{\mathrm{OR}}$ by interacting protein chains. $\mathbf{h}$ Mapping of interacting chain-ASU interactions onto ASU- $\mathrm{O}_{\mathrm{OR}}$. The interactions made by the neighbouring ASU chains are mapped onto ASU-O $\mathrm{O}_{\mathrm{OR}}$ using the same colour code as 'e'.
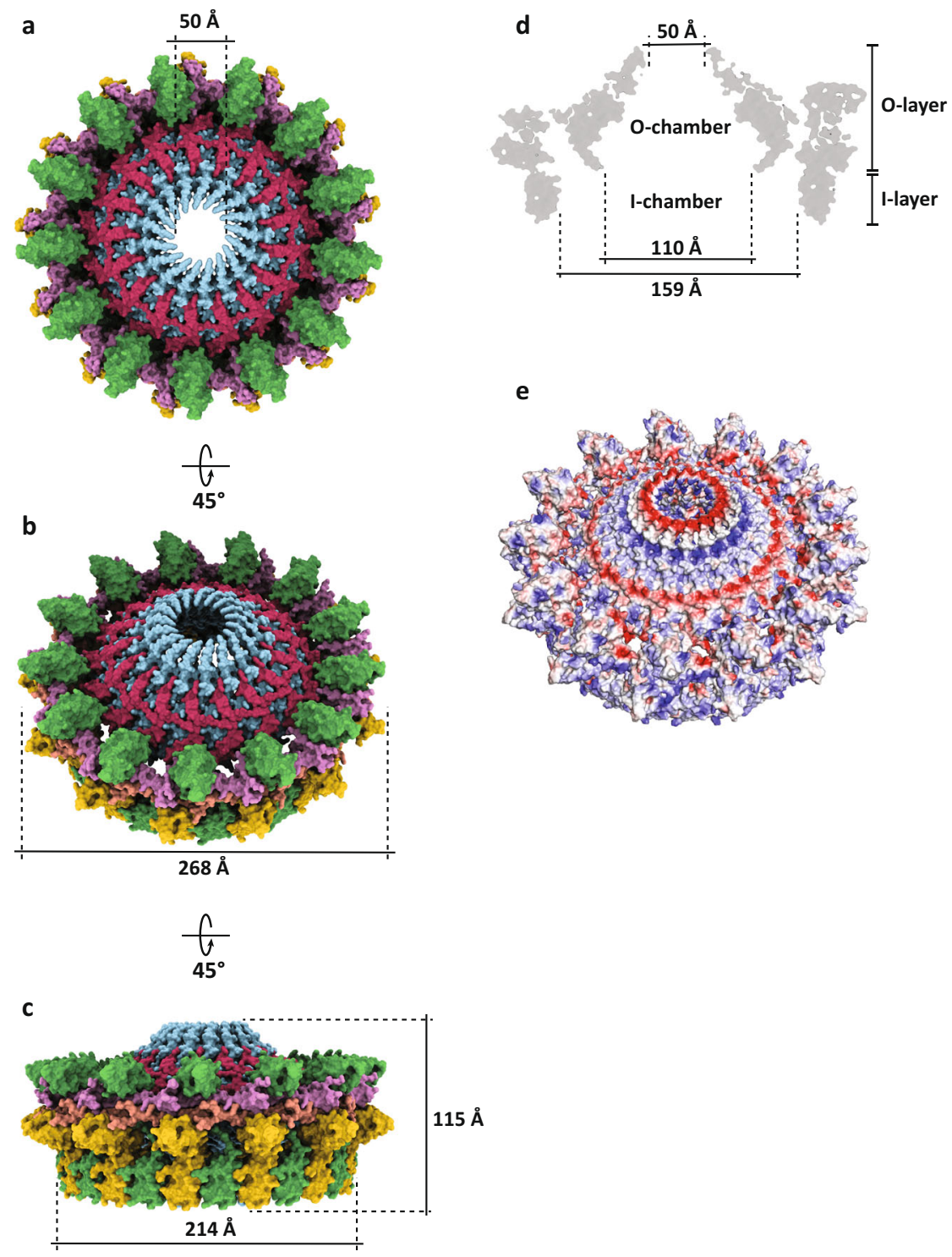

Fig. 5 Structure of the outer membrane core complex. a Top view of the structure of OMCC in surface representation with each protein within the complex coloured in their respective colours. b Tilt view of the structure in surface representation with the width of the O-layer. c Side view of the structure in surface representation with the overall height of the complex and the width of the I-layer. $\mathbf{d}$ Cut-away side view of the model with the dimensions at distinct positions of the inner channel and indicating specific structural features within the complex. e Distribution of surface charges on the OMCC structure. 


\begin{tabular}{|c|c|c|c|}
\hline & OMCC inner ring & OMCC outer ring & OMCC C1 \\
\hline \multicolumn{4}{|l|}{ Data collection and processing } \\
\hline Microscope & Titan Krios & Titan Krios & Titan Krios \\
\hline Camera & & & \\
\hline Voltage (kV) & 300 & 300 & 300 \\
\hline Electron exposure $\left(\mathrm{e}^{-} \AA^{-2}\right)$ & & & \\
\hline Pixel size $(\AA)$ & 1.08 & 1.08 & 1.08 \\
\hline Defocus range $(\mu \mathrm{m})$ & -0.7 to -3.0 & -0.7 to -3.0 & -0.7 to -3.0 \\
\hline Symmetry imposed & C17 & & \\
\hline Initial particle images & $1,445,958$ & $1,445,958$ & $1,445,958$ \\
\hline Final particle images & 74,956 & 298,235 & 95,177 \\
\hline FSC threshold & 0.143 & 0.143 & 0.143 \\
\hline Map resolution $(\AA)$ & 3.3 & 3.4 & 5.7 \\
\hline Map B factor & -74 & -93 & -304 \\
\hline \multirow{2}{*}{\multicolumn{4}{|c|}{$\begin{array}{l}\text { EIMUB code } \\
\text { Refinement and model validation }\end{array}$}} \\
\hline & & & \\
\hline Model versus data CC (mask) & 0.72 & 0.75 & $n / a$ \\
\hline Clash score & 13.73 & 13.82 & \\
\hline MolProbity score & 2.18 & 2.25 & \\
\hline Bond lengths rmsd $(\AA)$ & 0.007 & 0.005 & \\
\hline Bond angle rmsd $\left({ }^{\circ}\right)$ & 1.136 & 1.033 & \\
\hline Poor rotamers (\%) & 0 & & \\
\hline \multicolumn{4}{|l|}{ Ramachandran } \\
\hline & & 88.03 & \\
\hline Allowed (\%) & 9.3 & 11.97 & \\
\hline Outlier (\%) & & & \\
\hline PDB code & $70 K N$ & $70 \mathrm{KO}$ & \\
\hline
\end{tabular}

However, protein translocating T4SSs have been shown to assemble OMCCs with either homogeneous C14 symmetry as the bacterial killing system (i.e., $X$. citri) ${ }^{21}$, or variable symmetries of C13:C18 (L. pneumophila) $)^{33,34}$ and C14:C17 (H. pylori) ${ }^{36,37}$ between different complex layers. In our complex, however, a mismatch in symmetry is observed between two concentric $\mathrm{OMCC}_{\mathrm{IR}}(\mathrm{C} 17)$ and $\mathrm{OMCC}_{\mathrm{OR}}(\mathrm{C} 13)$ rings located within the same layer of the complex. This unique arrangement was concealed in the previous $\mathrm{OMCC}_{\mathrm{pED} 208}$ cryo-ET map due to low resolution and the imposed $\mathrm{C} 13$ symmetry during reconstruction. This arrangement may contribute to remarkable differences in protein stoichiometry within the complex when compared to other OMCCs ${ }^{17-21,33,34,36,37}$. Specifically, TraB, TraK and TraV are stoichiometrically related as $1: 1.53: 1.53$ with a total of 17:26:26 protein copies to shape the 2.1 MDa F-OMCC structure. This unusual stoichiometry could be rationalised by the differences in the symmetry between the $\mathrm{OMCC}_{\mathrm{IR}}$ and $\mathrm{OMCC}_{\mathrm{OR}}$, where 1:1 (TraB:TraV) per ASU exists in the OMCC C17 inner ring and a 1:2:2 (TraB:TraK:TraV) per ASU exists in the OMCC $\mathrm{C} 13$ outer ring. It is particularly noteworthy that the $\mathrm{OMCC}_{\mathrm{OR}}$ C13 symmetry could be expanded to C26 due to the presence of 26 copies of TraK $\mathrm{K}_{\mathrm{NTDs}}$ which make up the complete I-layer ring.

Within the structure, TraK adopts two distinct conformations where the NTDs and CTDs are connected by visible linkers physically connecting the I- and O-layer. In other OMCC structures, the absence of equivalent linker density from TraK homologues has been attributed to the axial flexibility between the I- and O-layer ${ }^{21}$. However, the F-OMCC shows to be rigid between the I- and O-layer with its flexibility provided by the radial TraV connections between the inner and the outer rings. The position of these TraV flexible linkers suggest that nonsynchronised rotational movements could happen as a consequence of the dynamic freedom between the two rings. In addition, TraV has a central role in scaffolding the F-OMCC structure by creating a large mesh at the inner ring and a continuous belt holding all the TraK CTDs at the outer ring. Central in maintaining the integrity of this large mesh and thus OMCC symmetry, is the interchain di-sulphide bond interactions established by $\mathrm{TraV}_{\mathrm{Cys} 27}$ and $\mathrm{TraV}_{\mathrm{Cys} 35}$. These TraV cysteine residues, only conserved in members of the F-T4SS family (Supplementary Fig. 2d), are responsible for the correct localisation of TraV to the outer membrane, efficient DNA conjugation to the recipient cell and sensitivity to bacteriophage infection ${ }^{35}$. TraV is also key in providing an interaction hub to other Tra/Trb proteins (e.g., TraH, TraF, TraW and TrbC) to the OMCC ${ }^{38,39}$. The presence of these interacting partners could stabilise the flexible regions of TraV for which we did not assign a sequence. TraB is the most structurally conserved protein at the O-layer, and interactions at the I-layer have only been observed in OMCCs structures of $X$. citri and $\mathrm{F}-\mathrm{OMCC}^{21}$. In the case of the X. citri OMCC a protein helix was observed at the base of the I-layer, but the linkers connecting to the rest of the VirB10 proteins at the O-layer were absent. However, in the F-OMCC a continuous density could be observed for a few TraB protein chains suggesting that the eight residues proline-rich sequence between the $\beta 1$ - and $\beta 2$-strands could indeed connect both strands (Supplementary Fig. 2a). Yet, this density could not be observed for most of the TraB proteins implying that the proteins experience variable levels of flexibility in the outer ring channel surface. This lack of density could be either explained by translational movements of the protein chains along the $\mathrm{OMCC}_{\mathrm{OR}}$ channel surface or, by a "sliding" mechanism that changes the protein register to accommodate rotational movements undertaken by the $\mathrm{OMCC}_{\mathrm{IR}}$. Notably, the interaction between TraB $\beta 1$ and TraK $\beta 4$ strands are mediated exclusively by main chain interactions possibly suggesting transient contacts between the two proteins (Fig. 3 and Supplementary Fig. 3b). The location of $\operatorname{TraB} \beta 1$ in the inner side of the $\mathrm{OMCC}_{\mathrm{OR}}$ was not entirely unexpected and is in agreement with previous observations in the $X$. citri OMCC structure, where a section of VirB10 (residues 150-161) contacts the inner wall of the OMCC I-layer ${ }^{21}$. The interaction between TraK and TraB was reported previously $^{29}$. Yeast-two-hybrid results show that a TraB region incorporating the $\beta 1$ residues, is the only region capable of interacting with the $\beta 4$ of $\operatorname{TraK}^{29}$. Overall, the extensive flexibility observed at various regions of the OMCC, dictated by the TraB and TraV proteins, suggest a highly dynamic complex capable of adapting to an emerging F-pilus during biogenesis and, also playing a central role during filament extension and retraction.

In summary, we report the high-resolution structure of a conjugative T4SS outer membrane core complex encoded by the iconic F plasmid. The structure markedly differs from previously reported OMCCs due to its unique structural organisation with two concentric rings related by mismatched symmetries, radial structural flexibility and defined connections between the O- and I-layer of the complex. Overall, the structure provides exciting new insights into the dynamics mediating F-pilus extension/ retraction and ultimately DNA transfer during conjugation. This work sets the stage for future investigations aiming to understand the mechanistic details of antimicrobial resistance gene transfer among bacteria.

\section{Methods}

Outer membrane core-complex expression and purification. The sequence coding for traB-strep, traK and traV was cloned as a polycistronic operon into pBAD24 vector and transformed into TOP10 cells. Protein overexpression was induced at $\mathrm{OD}_{600}=0.6$ by addition of $0.2 \% \mathrm{w} / \mathrm{v}$ arabinose for $18 \mathrm{~h}$ at $18^{\circ} \mathrm{C}$. The cells were harvested by centrifugation at $7000 \times g, 20 \mathrm{~min}$ at $4{ }^{\circ} \mathrm{C}$, and the pellet was resuspended in $50 \mathrm{mM}$ Tris- $\mathrm{HCl}(\mathrm{pH} 7.5), 200 \mathrm{mM} \mathrm{NaCl}, 1 \mathrm{mM}$ EDTA, $0.2 \mathrm{mg} \mathrm{ml}^{-1}$ lysozyme, protease inhibitor tablet. Following lysis by sonication on ice, cellular debris was removed by centrifugation at $35,000 \times g$ for $20 \mathrm{~min}$. The crude membrane fraction was isolated by ultracentrifugation at $120,000 \times g$ for $1 \mathrm{~h}$. Membrane proteins were solubilised with gentle agitation for $1 \mathrm{~h}$ in $50 \mathrm{mM}$ Tris- $\mathrm{HCl}(\mathrm{pH} 7.5), 300 \mathrm{mM}$ $\mathrm{NaCl}, 1 \mathrm{mM}$ EDTA, 0.8\% w/v LDAO (Anatrace) and 1\% w/v DDM (Anatrace). The insoluble material was pelleted by ultracentrifugation at $100,000 \times g$ for $40 \mathrm{~min}$ and the supernatant was loaded onto a Strep-Tactin Sepharose affinity column (GE Healthcare). The column was washed with $50 \mathrm{mM}$ Tris- $\mathrm{HCl}$ (pH 7.5), $300 \mathrm{mM} \mathrm{NaCl}$ and $0.23 \% \mathrm{w} / \mathrm{v}$ LDAO and, the protein eluted in the same buffer supplemented with $10 \mathrm{mM}$ D-desthiobiotin (IBA). The eluted proteins were loaded onto a Superose $6 \mathrm{GL}$ 10/300 (GE Healthcare) equilibrated with $50 \mathrm{mM}$ Tris- $\mathrm{HCl}$ (pH 7.5), $300 \mathrm{mM} \mathrm{NaCl}$ and $0.23 \% \mathrm{w} / \mathrm{v} \mathrm{LDAO}$, following concentration by centrifugal concentrator with 


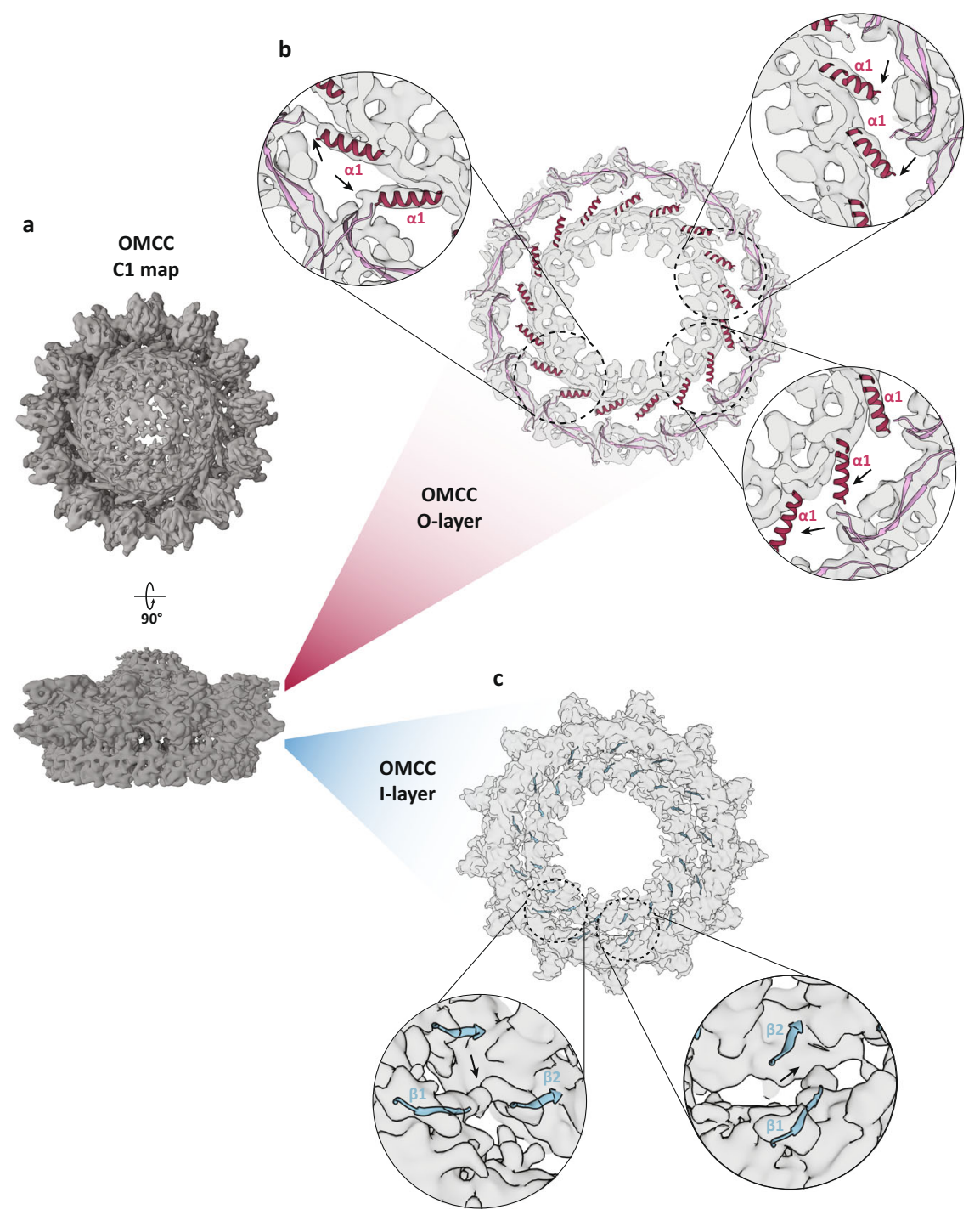

Fig. 6 OMCC asymmetric map and complex flexibility. a Overview of the top and side views of the OMCC electron density map reconstructed without any imposed symmetry determined at a resolution of $5.7 \AA$. b Horizontal slice of the OMCC C1 map (contour level 0.34) taken at the indicated O-layer location. Each inset shows different levels of electron densities (indicated by arrows) in the connections between the TraV1 ${ }_{\text {CTD }}$ linker (residues $69-80$ ) located at the OMCC $\mathrm{OR}_{\mathrm{R}}$ and the TraV $\alpha 1$ helix located at the $\mathrm{OMCC}_{\mathrm{IR}}$. $\mathbf{c}$ Horizontal slice of the OMCC C1 map (contour level 0.16) taken at the indicated I-layer location. Each inset shows different levels of electron densities (indicated by arrows) in the connections between the TraB $\beta 1$ located at the $\mathrm{OMCC}_{\mathrm{OR}}$ and TraB $\beta 2$ located at the $\mathrm{OMCC}_{\mathrm{OR}}$.

$100 \mathrm{kDa}$ molecular weight cut-off. The proteins were analysed by SDS-PAGE and Coomassie blue staining.

Electron microscopy sample preparation and data collection. To assess the F-OMCC purity and homogeneity after size-exclusion chromatography (SEC), $10 \mu \mathrm{l}$ of protein sample was applied onto glow-discharged carbon-coated copper grids (300 mesh, Agar Scientific). After incubation for $2 \mathrm{~min}$ at room temperature, grids were washed twice with $10 \mu \mathrm{l}$ of water, blotted with filter paper and stained for $1 \mathrm{~min}$ with $2 \% \mathrm{w} / \mathrm{v}$ uranyl acetate. Excess stain was removed by a final blotting step and grids were let to dry before imaging. Negative-stain (NS) images of the F-OMCC were acquired on a FEI Tecnai G2 Spirit operating at $120 \mathrm{kV}$ equipped with a $\mathrm{LaB}_{6}$ filament and a $\mathrm{CCD} 4 \mathrm{k} \times 4 \mathrm{k}$ camera. For F-OMCC structure determination, $4 \mu \mathrm{l}$ of the sample, previously assessed by NS, was adjusted to $0.1 \mathrm{mg} / \mathrm{ml}$ and applied onto glow-discharged Lacey copper grids with ultrathin carbon film (300 mesh, Agar Scientific). Samples were vitrified in liquid ethane using a Leica automatic plunge freezer EM GP2 with a 2.4-2.8 s blot time under $85 \%$ relative humidity at $4{ }^{\circ} \mathrm{C}$. The frozen girds were checked for sample concentration and ice thickness using the Jeol 2100 plus microscope. The grids with ideal protein concentration and ice thickness were used for data acquisition at LonCEM (London Consortium EM, Francis Crick Institute) using a FEI Titan Krios operating at $300 \mathrm{kV}$. Images were collected automatically using EPU software (FEI) on a Gatan $\mathrm{K} 3$ detector in counting mode with a pixel size of $1.08 \AA$. A total of 11588 movies were recorded with a nominal defocus range of $\sim-0.7$ to $-3.0 \mu \mathrm{m}$. Each image consisted on a movie stack of 38 frames with a total dose of $50 \mathrm{e}^{-} / \AA^{2}$ over $3.9 \mathrm{~s}$

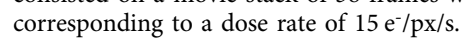

Cryo-EM image processing and reconstruction. All image processing was done with CryoSparc 40 (v3.1.0) unless otherwise mentioned. The movie stacks were aligned and summed using patch motion correction, and CTF was estimated using the patch CTF estimation function. After screening the micrographs for good Thon Rings and ideal ice thickness, 10,911 images remained in the dataset for further processing. In total, 3506 particles were manually picked and classified to generate $2 \mathrm{D}$ class references for automated particle picking of the entire dataset. After establishing the correct auto-picking parameters using a small number of images, a total of 1,445,958 particles were auto-picked from the entire dataset and extracted using a box size of $480 \times 480$ pixels. Low-quality particles were removed after several rounds of 2D classification, resulting in a stack of 298,235 particles with defined $\mathrm{OMCC}_{\mathrm{OR}}$ features. Further rounds of $2 \mathrm{D}$ classification, improved the visual details of the $\mathrm{OMCC}_{\mathrm{IR}}$ and resulted on a final stack of 74,956 particles. After visual inspection of the $2 \mathrm{D}$ classes, we determined that we had two different symmetries in the complex, $\mathrm{C} 13$ for the $\mathrm{OMCC}_{\mathrm{OR}}$ and $\mathrm{C} 17$ for the $\mathrm{OMCC}_{\mathrm{IR}}$. Ab-initio maps were generated and all $\mathrm{OMCC}_{\mathrm{OR}}$ particles were subjected to $3 \mathrm{D}$ homogeneous refinement (with $\mathrm{C} 13$ symmetry applied) with a solvent mask (5 pixels extension and 6 pixels of drop off) encompassing the $\mathrm{OMCC}_{\mathrm{OR}}$. Similarly, all $\mathrm{OMCC}_{\mathrm{IR}}$ particles were subjected to the same 3D procedure, this time with C17 symmetry applied to the inner-ring with a solvent mask with five pixels extension and six 
pixels of drop off applied. Simultaneously, 95177 particles were used to generate an unsymmetrized map confirming the existence of the $\mathrm{C} 13$ and $\mathrm{C} 17$ symmetries at $\mathrm{OMCC}_{\mathrm{OR}}$ and $\mathrm{OMCC}_{\mathrm{IR}}$ respectively. Further, a B factor of $-74,-93$ and -304 was applied to the $\mathrm{OMCC}_{\mathrm{IR}}$, OMCC $\mathrm{OR}$ and $\mathrm{OMCC}_{\mathrm{C} 1}$ maps, improving the overall resolution to $3.3 \AA, 3.4 \AA$ and $5.7 \AA$ ( $\mathrm{FSC}=0.143$ ), respectively. The local resolution estimation in the $\mathrm{OMCC}_{\mathrm{OR}}$ and $\mathrm{OMCC}_{\mathrm{IR}}$ maps was performed in Relion 3.141. Statistics for data collection and 3D refinement are included in Supplementary Table 1 .

Model building and refinement. Model building started with identifying the single asymmetric unit (ASU) in both the $\mathrm{OMCC}_{\mathrm{OR}}$ and the $\mathrm{OMCC}_{\mathrm{IR}}$ maps and building into the density using both maps. For the inner ring once the ASU was identified, single helices were placed manually into the density using $\operatorname{Coot}^{42}$. Using these helices as templates, the remainder of the structure was built manually by extending the chains at both the N and C-terminus. Once a single unit of TraB was built, the various chains were merged to make a single chain of TraB protein. The $\mathrm{OMCC}_{\mathrm{IR}}$ ASU had an extra density corresponding to an alpha helix. A polyalanine helix was placed into the density and the chain was extended at the $\mathrm{N}$-terminus till the end of the continuous density. First, bulky side chains were assigned and then, by identifying connecting sequences, the $\mathrm{N}$-terminus of the TraV was built in the density. The correct side chains were assigned to the polyalanine chain, thereby allowing a single ASU of the OMCC $_{I R}$ to be built. This central ASU was copied and manually placed to occupy two clockwise and anticlockwise unit densities. The resulting ASU, $+1,+2,-1$ and -2 model was used for refining the central ASU. The model was subjected to several iterative rounds of real space refinement using Phenix ${ }^{43}$ and progress in refinement was tracked using Ramachandran plot and Molprobity ${ }^{44}$. After successful refinement of the central ASU model, a PDB file with two adjacent ASUs were generated by fitting into their respective density using CHIMERA ${ }^{45}$. The rotation and translation parameters of these two chains were then calculated using the programme LSQKAB ${ }^{46}$. A PDB coordinate file was then generated using the rotation and translation parameters obtained with the programme PDBSET ${ }^{47}$ with seventeen ASUs making the full inner ring structure.

In the case of the outer ring, the VirB9 model of the X. citri OMCC structure ${ }^{21}$ was used as a template to build into the density. A single TraK1 $1_{\mathrm{NTD}}$ was manually built using $\operatorname{Coot}^{42}$ and this was copied to fit into the TraK2 $2_{\text {NTD }}$ density part of the same ASU. The TraK2 $2_{\text {CTD }}$ was built first by extending the chain from the I-layer and placing the poly-alanine alpha helix into its respective density. Once the TraK2 $2_{\text {CTD }}$ chain was built, a copy of the same chain was placed into the respective density in the TraK1 $1_{\text {СтD. }}$. Clear continuous density was visible between the $\mathrm{TraK}_{\mathrm{NTD}}$ and TraK1 $1_{\mathrm{CTD}}$ densities wherein a poly-alanine chain was manually built. Amino acids with bulky side chains were assigned first and by identifying the connecting sequence between two bulky residues the correct sequence was assigned. This was built further to occupy the continuous density thereby, resulting in two TraV chains. Also, a TraV sequence was built into a connecting density adjacent to the TraK1 $1_{\mathrm{CTD}}$. Finally, an extra density radially located inside of the I-layer section of the outer ring was assigned to TraB and built manually using $\operatorname{Coot}^{42}$. Once the entire ASU was built, it was copied and manually placed to occupy one ASU clockwise and one ASU anti-clockwise unit densities. This ASU, +1 and -1 was used to refine the central ASU chains. These three ASU unit was subjected to several rounds of real space refinement using Phenix ${ }^{43}$ and the progress was monitored using Ramachandran plot and Molprobity ${ }^{44}$. Once the ASU was successfully refined, a PDB coordinate file containing two adjacent ASUs was created by fitting the central ASU model into two adjacent densities using Chimera ${ }^{45}$. Similar to the inner ring, the rotation and translation parameters were calculated using $\mathrm{LSQKAB}^{46}$ and a coordinate file with thirteen ASUs were generated using PDBSET ${ }^{47}$. Two separate coordinate files corresponding to the $\mathrm{OMCC}_{\mathrm{IR}}$ and $\mathrm{OMCC}_{\mathrm{OR}}$ were submitted to the protein data bank with the entry codes $7 \mathrm{OKN}$ and $7 \mathrm{OKO}$, respectively.

Structure analysis and presentation. The analysis and visualisation of the cryoEM maps and atomic models were done using Chimera ${ }^{45}$, ChimeraX ${ }^{48}$, PyMol (Molecular Graphics System, Schrödinger), and PDBePISA (https://www.ebi.ac.uk/ pdbe/pisa/).

Reporting summary. Further information on research design is available in the Nature Research Reporting Summary linked to this article.

\section{Data availability}

The data that support this study are available from the corresponding authors upon reasonable request. The atomic coordinates have been deposited at the Protein Data Bank with accession codes $7 \mathrm{OKN}\left(\mathrm{OMCC}_{\mathrm{IR}}\right)$ and $7 \mathrm{OKO}\left(\mathrm{OMCC}_{\mathrm{OR}}\right)$. The density maps have been deposited at the Electron Microscopy Data Bank with accession codes EMD-12962 $\left(\mathrm{OMCC}_{\mathrm{IR}}\right)$, EMD-12963 (OMCC $\left.\mathrm{OR}\right)$ and EMD-13231 $\left(\mathrm{OMCC}_{\mathrm{C} 1}\right)$.

Received: 26 July 2021; Accepted: 3 November 2021; Published online: 25 November 2021

\section{References}

1. Lederberg, J. \& Tatum, E. L. Gene recombination in Escherichia coli. Nature 158, 558 (1946).

2. Koraimann, G. Spread and persistence of virulence and antibiotic resistance genes: a ride on the F plasmid conjugation module. EcoSal Plus 8, 1-23 (2018).

3. Blair, J. M., Webber, M. A., Baylay, A. J., Ogbolu, D. O. \& Piddock, L. J. Molecular mechanisms of antibiotic resistance. Nat. Rev. Microbiol. 13, 42-51 (2015).

4. Thomas, C. M. \& Nielsen, K. M. Mechanisms of, and barriers to, horizontal gene transfer between bacteria. Nat. Rev. Microbiol. 3, 711-721 (2005).

5. Costa, T. R. et al. Secretion systems in Gram-negative bacteria: structural and mechanistic insights. Nat. Rev. Microbiol. 13, 343-359 (2015).

6. Alvarez-Martinez, C. E. \& Christie, P. J. Biological diversity of prokaryotic type IV secretion systems. Microbiol. Mol. Biol. Rev.: MMBR 73, 775-808 (2009).

7. Souza, D. P. et al. Bacterial killing via a type IV secretion system. Nat. Commun. 6, 6453 (2015).

8. Odenbreit, S. et al. Translocation of Helicobacter pylori CagA into gastric epithelial cells by type IV secretion. Science 287, 1497-1500 (2000).

9. Isaac, D. T. \& Isberg, R. Master manipulators: an update on Legionella pneumophila $\mathrm{Icm} /$ Dot translocated substrates and their host targets. Future Microbiol. 9, 343-359 (2014).

10. Siamer, S. \& Dehio, C. New insights into the role of Bartonella effector proteins in pathogenesis. Curr. Opin. Microbiol. 23, 80-85 (2015).

11. Kotob, S. I., Hausman, S. Z. \& Burns, D. L. Localization of the promoter for the ptl genes of Bordetella pertussis, which encode proteins essential for secretion of pertussis toxin. Infect. Immun. 63, 3227-3230 (1995).

12. Waksman, G. From conjugation to T4S systems in Gram-negative bacteria: mechanistic biology perspective. EMBO Rep. 20, e47012 (2019).

13. Low, H. H. et al. Structure of a type IV secretion system. Nature 508, 550-553 (2014).

14. Waksman, G. \& Orlova, E. V. Structural organisation of the type IV secretion systems. Curr. Opin. Microbiol. 17, 24-31 (2014).

15. Hospenthal, M. K., Costa, T. R. D. \& Waksman, G. A comprehensive guide to pilus biogenesis in Gram-negative bacteria. Nat. Rev. Microbiol. 15, 365-379 (2017).

16. Ilangovan, A., Connery, S. \& Waksman, G. Structural biology of the Gramnegative bacterial conjugation systems. Trends Microbiol. 23, 301-310 (2015).

17. Gordon, J. E. et al. Use of chimeric type IV secretion systems to define contributions of outer membrane subassemblies for contact-dependent translocation. Mol. Microbiol. 105, 273-293 (2017).

18. Fronzes, R. et al. Structure of a type IV secretion system core complex. Science 323, 266-268 (2009).

19. Chandran, V. et al. Structure of the outer membrane complex of a type IV secretion system. Nature 462, 1011-1015 (2009).

20. Rivera-Calzada, A. et al. Structure of a bacterial type IV secretion core complex at subnanometre resolution. EMBO J. 32, 1195-1204 (2013).

21. Sgro, G. G. et al. Cryo-EM structure of the bacteria-killing type IV secretion system core complex from Xanthomonas citri. Nat. Microbiol. 3, 1429-1440 (2018).

22. Fernandez, D., Spudich, G. M., Zhou, X. R. \& Christie, P. J. The Agrobacterium tumefaciens VirB7 lipoprotein is required for stabilization of VirB proteins during assembly of the T-complex transport apparatus. J. Bacteriol. 178, 3168-3176 (1996).

23. Baron, C., Thorstenson, Y. R. \& Zambryski, P. C. The lipoprotein VirB7 interacts with VirB9 in the membranes of Agrobacterium tumefaciens. J. Bacteriol. 179, 1211-1218 (1997).

24. Sgro, G. G. et al. Bacteria-killing type IV secretion systems. Front. Microbiol. 10, 1078 (2019)

25. Souza, D. P. et al. A component of the Xanthomonadaceae type IV secretion system combines a VirB7 motif with a N0 domain found in outer membrane transport proteins. PLoS Pathog. 7, e1002031 (2011).

26. Strahilevitz, J., Jacoby, G. A., Hooper, D. C. \& Robicsek, A. Plasmid-mediated quinolone resistance: a multifaceted threat. Clin. Microbiol. Rev. 22, 664-689 (2009).

27. Lu, J. et al. Analysis and characterization of the IncFV plasmid pED208 transfer region. Plasmid 48, 24-37 (2002).

28. Costa, T. R. D. et al. Type IV secretion systems: advances in structure, function, and activation. Mol. Microbiol. 115, 436-452 (2021).

29. Harris, R. L., Hombs, V. \& Silverman, P. M. Evidence that F-plasmid proteins TraV, TraK and TraB assemble into an envelope-spanning structure in Escherichia coli. Mol. Microbiol. 42, 757-766 (2001).

30. Costa, T. R. D. et al. Structure of the bacterial sex F pilus reveals an assembly of a stoichiometric protein-phospholipid complex. Cell 166, 1436-1444 (2016).

31. Hu, B., Khara, P. \& Christie, P. J. Structural bases for F plasmid conjugation and F pilus biogenesis in Escherichia coli. Proc. Natl Acad. Sci. USA 116 14222-14227 (2019). 
32. Ghosal, D. et al. Molecular architecture, polar targeting and biogenesis of the Legionella Dot/Icm T4SS. Nat. Microbiol. 4, 1173-1182 (2019).

33. Durie, C. L. et al. Structural analysis of the Legionella pneumophila Dot/Icm type IV secretion system core complex. eLife 9, e59530 (2020).

34. Sheedlo, M. J. et al. Cryo-EM reveals new species-specific proteins and symmetry elements in the Legionella pneumophila Dot/Icm T4SS. eLife 10, e70427 (2021).

35. Harris, R. L. \& Silverman, P. M. Roles of internal cysteines in the function, localization, and reactivity of the TraV outer membrane lipoprotein encoded by the F plasmid. J. Bacteriol. 184, 3126-3129 (2002).

36. Chung, J. M. et al. Structure of the Helicobacter pylori Cag type IV secretion system. eLife 8, e47644 (2019).

37. Sheedlo, M. J. et al. Cryo-EM reveals species-specific components within the Helicobacter pylori Cag type IV secretion system core complex. eLife 9, e59495 (2020).

38. Arutyunov, D., Arenson, B., Manchak, J. \& Frost, L. S. F plasmid TraF and $\mathrm{TraH}$ are components of an outer membrane complex involved in conjugation. J. Bacteriol. 192, 1730-1734 (2010).

39. Koch, B. et al. Protein interactions within and between two F-type type IV secretion systems. Mol. Microbiol. 114, 823-838 (2020).

40. Punjani, A., Rubinstein, J. L., Fleet, D. J. \& Brubaker, M. A. cryoSPARC: algorithms for rapid unsupervised cryo-EM structure determination. Nat. Methods 14, 290-296 (2017).

41. Zivanov, J. et al. New tools for automated high-resolution cryo-EM structure determination in RELION-3. eLife 7, e42166 (2018).

42. Emsley, P., Lohkamp, B., Scott, W. G. \& Cowtan, K. Features and development of Coot. Acta Crystallogr D. Biol. Crystallogr 66, 486-501 (2010).

43. Adams, P. D. et al. PHENIX: a comprehensive Python-based system for macromolecular structure solution. Acta Crystallogr D. Biol. Crystallogr 66, 213-221 (2010).

44. Chen, V. B. et al. MolProbity: all-atom structure validation for macromolecular crystallography. Acta Crystallogr D. Biol. Crystallogr 66, 12-21 (2010).

45. Pettersen, E. F. et al. UCSF Chimera-a visualization system for exploratory research and analysis. J. Comput. Chem. 25, 1605-1612 (2004).

46. Kabsch, W. A solution for the best rotation to relate two sets of vectors. Acta Crystallogr. Sect. A 32, 922-923 (1976).

47. Winn, M. D. et al. Overview of the CCP4 suite and current developments. Acta Crystallogr D. Biol. Crystallogr 67, 235-242 (2011).

48. Goddard, T. D. et al. UCSF ChimeraX: meeting modern challenges in visualization and analysis. Protein Sci. 27, 14-25 (2018).

\section{Acknowledgements}

Imaging was done at the eBIC (Diamond, UK) and LonCEM (Francis Crick Institute, UK). We thank Diamond for access and support of the Cryo-EM facilities at the

UK national electron bio-imaging centre (eBIC), proposal EM18659, funded by the
Wellcome Trust, MRC, and BBSRC. We thank Nora Cronin for the help with data collection at LonCEM and Paul Simpson (Electron Microscopy Facility, Centre for Structural Biology, Imperial College London) for in-house EM support. We also thank Simona Draganova for technical support. This work was supported by the Welcome Trust Award 215164/Z/18/Z to T.R.D.C.

\section{Author contributions}

A.I. and T.R.D.C. designed the research. H.A. purified the OMCC sample, performed negative-stain imaging and initial cryo-EM sample optimisation. A.I. prepared cryo-EM grids. T.R.D.C. collected, processed and solved structures. A.I. built the OMCC structures. A.I. and T.R.D.C. wrote the manuscript with contributions from H.A.

\section{Competing interests}

The authors declare no competing interests.

\section{Additional information}

Supplementary information The online version contains supplementary material available at https://doi.org/10.1038/s41467-021-27178-8.

Correspondence and requests for materials should be addressed to Aravindan Ilangovan or Tiago R. D. Costa.

Peer review information Nature Communications thanks the anonymous reviewers for their contribution to the peer review of this work.

Reprints and permission information is available at http://www.nature.com/reprints

Publisher's note Springer Nature remains neutral with regard to jurisdictional claims in published maps and institutional affiliations.

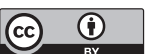

Open Access This article is licensed under a Creative Commons Attribution 4.0 International License, which permits use, sharing, adaptation, distribution and reproduction in any medium or format, as long as you give appropriate credit to the original author(s) and the source, provide a link to the Creative Commons license, and indicate if changes were made. The images or other third party material in this article are included in the article's Creative Commons license, unless indicated otherwise in a credit line to the material. If material is not included in the article's Creative Commons license and your intended use is not permitted by statutory regulation or exceeds the permitted use, you will need to obtain permission directly from the copyright holder. To view a copy of this license, visit http://creativecommons.org/ licenses/by/4.0/.

(C) The Author(s) 2021, corrected publication 2022 